\title{
EL TURISMO COMO DINAMIZADOR DE LAS ECONOMÍAS REGIONALES: EL CASO DE LA COMUNIDAD MAPUCHE PUEL
}

\section{TOURISM AS A DYNAMISING FACTOR OF REGIONAL ECONOMIES: THE CASE OF THE MAPUCHE PUEL COMMUNITY}

\author{
Micaela Abigail Spinelli \\ Escuela de Economía y Negocios \\ Universidad Nacional de San Martín \\ San Martín, Buenos Aires, Argentina \\ mspinelli@unsam.edu.ar
}

Fecha de recepción: 10/09/2020 - Fecha de revisión: 29/12/2020 - Fecha de aprobación: 04/01/2021

DOI: https://doi.org/10.36995/j.visiondefuturo.2021.25.02.003.es

\section{RESUMEN}

El turismo de base comunitaria es una actividad que, según Sansolo y Burstzyn (2009), tiene como componentes la conservación del medio ambiente, la visibilización de la identidad cultural y la generación de beneficios directos para las comunidades.

Asimismo la economía depende de la actividad turística, principalmente a través de la recepción de divisas y de la creación de empleo que puede surgir a partir del desarrollo de la misma.

Esta investigación pretende demostrar que hasta hace pocos años la comunidad mapuche se dedicaba exclusivamente a la cría de animales, sin contemplar otras posibilidades para la dinamización de su economía. Sin embargo, han notado la necesidad de cambiar su paradigma y desde el año 2000 se encuentra en funcionamiento el primer y único Parque de Nieve administrado por una comunidad indígena, ubicado en el Cerro Batea Mahuida, localidad de Villa Pehuenia, Neuquén, Argentina.

Con el análisis del caso se observa que, si bien la comunidad ha podido diversificar su mercado logrando así su autosustento, el potencial emprendimiento no logra fortalecerse. Por tal motivo, se propone una serie de recomendaciones a fin de revertir dicho escenario. Éstas pretenden aprovechar los recursos actuales y generar alianzas con distintos organismos propiciando un modelo de desarrollo que promueva la inserción de sus miembros a una actividad que beneficia el crecimiento de toda la localidad.

PALABRAS CLAVE: Desarrollo Local; Economía Regional; Pueblos Originarios; Turismo Comunitario.

\section{ABSTRACT}

According to Sansolo and Burstzyn (2009), community-based tourism is an activity in wich the conservation of the environment, the visibility of cultural identity and the generation “Visión de Futuro" Año 18, Volumen N²5 N², Edición Especial-III Congreso Regional de Economía del Norte Grande-Pág 56-79 URL de la Revista: http://visiondefuturo.fce.unam.edu.ar/index.php/visiondefuturo/index URL del Documento: https://visiondefuturo.fce.unam.edu.ar/index.php/visiondefuturo/issue/view/20 ISSN 1668 - 8708 - Versión en Línea E-mail: revistacientifica@fce.unam.edu.ar 
of direct benefits for the communities are their main components. Likewise, their economy depends on tourism foreign exchange reception and the creation of jobs from its development.

This research aims to show that Mapuches only raised animals until only a few years ago. However, they have noticed the need to change their paradigm. The first and only Snow Park managed by Mapuches has been working since 2000. It is located in Cerro Batea Mahuida, Villa Pehuenia (Argentina) where they have known how to take advantage of nature's resources without damaging it.

The analysis of this case shows that although Mapuche community has been able to diversify its market thus achieving its self-sustenance, the potential undertaking does not manage to strengthen. For this reason, this work proposes a series of recommendations in order to reverse this scenario by taking advantage of its current resources and generating alliances with different organizations that further a development model in wich the insertion of its members to the activity benefits the growth of the entire town.

KEY WORDS: Local Development; Regional Economy; Communities; Community Tourism.

\section{INTRODUCCIÓN}

El cerro Batea Mahuida es, en realidad, un volcán inactivo. Etimológicamente el topónimo Mahuida-originalmente "mawida"-significa "cerro" en mapudungun (lenguaje del pueblo mapuche) y Batea es el nombre que se le dio por la forma del hueco que quedó en el cerro cuando se produjo la erupción del volcán.

La riqueza natural de este sitio ubicado en el límite entre Argentina y Chile, específicamente en la localidad de Villa Pehuenia, se conjuga con la historia y cultura de la Comunidad Mapuche Puel. Desde que el volcán se apagó y formó en su cráter una laguna, los mapuches, como pobladores históricos de estas tierras se establecieron en la localidad, a fines del siglo XIX. Promediando la década de los '90 surgió el deseo y la necesidad de poder realizar otras actividades además de criar ganado y estas circunstancias generaron las condiciones para el surgimiento del único Parque de Nieve en el mundo administrado por mapuches.

Es notable que, mayormente en invierno, el peso del Cerro Batea Mahuida es determinante para la economía del municipio. Es decir que la labor de los mapuches es fundamental para el funcionamiento del Parque y si bien su actividad es pionera y se particulariza por ser la única comunidad indígena en administrar un parque de nieve, todavía deben trabajar en cómo ofrecer mejores servicios. Es allí cuando el papel del estado es primordial. Tal como se destaca en la Objetivo de Desarrollo Sostenible (de ahora en más,

\footnotetext{
"Visión de Futuro" Año 18, Volumen N²5 N², Edición Especial-III Congreso Regional de Economía del Norte Grande-Pág 56-79 URL de la Revista: http://visiondefuturo.fce.unam.edu.ar/index.php/visiondefuturo/index

URL del Documento: https://visiondefuturo.fce.unam.edu.ar/index.php/visiondefuturo/issue/view/20

ISSN 1668 - 8708 - Versión en Línea

E-mail: revistacientifica@fce.unam.edu.ar
} 
ODS) número 8 -trabajo decente y crecimiento económico- (Naciones Unidas, 2015) la creación de condiciones y oportunidades laborales, son elementales para estimular el crecimiento económico sostenido e inclusivo. Meta que la comunidad ha buscado alcanzar, pero que aún no ha logrado de manera efectiva y constante. $Y$ más aún, al considerar otra característica que se destaca entre las fortalezas que el emprendimiento contiene es el hecho de que han sabido aprovechar los recursos de la naturaleza sin dañar a la misma ya que más allá de su altura (1900 m.s.n.m. aproximadamente) el volcán cuenta con nieve temprana y en gran cantidad, lo que hace innecesario la utilización de nieve artificial.

\section{DESARROLLO}

\section{Alcance del presente trabajo}

A partir de lo expuesto, el presente trabajo pretende elaborar un diagnóstico de la coyuntura turística de la Villa y del Parque de Nieve, abordando el mismo a través de metodologías cuantitativas y cualitativas. A partir de esta información, se identifican las necesidades que presenta la Comunidad Mapuche Puel en cuatro escenarios (económico, social, ambiental y político), para finalmente proponer una serie de recomendaciones enmarcadas en el desarrollo de objetivos, actuaciones e instrumentos de política turística con el objetivo último de potenciar el desarrollo turístico de la comunidad Mapuche Puel en la localidad neuquina. Para ello se tomarán en cuenta los siguientes objetivos:

Objetivo general: mejorar la competitividad y las condiciones que desarrolla el sector turístico de Villa Pehuenia a fin de potencializar el desarrollo del turismo comunitario de la localidad.

Objetivos específicos

Investigar y diagnosticar la coyuntura económica y turística de la localidad de Villa Pehuenia;

Identificar la problemática que enfrenta la comunidad Mapuche Puel focalizando la atención en el Parque de Nieve;

- Determinar las actuaciones e instrumentos a fin de lograr la implementación de dichos objetivos.

\section{Planteamiento del problema}

Hemos observado como una comunidad descendiente de pueblos originarios ha podido diversificar su mercado, basado originalmente en la venta de artesanías y cría de ganado, hacia el desarrollo de un emprendimiento turístico. Este cambio les permitió alcanzar su autosustento e inclusión al resto de la sociedad. Pero este potencial, tanto natural -el volcán-

\footnotetext{
"Visión de Futuro" Año 18, Volumen N²5 N², Edición Especial-III Congreso Regional de Economía del Norte Grande-Pág 56-79 URL de la Revista: http://visiondefuturo.fce.unam.edu.ar/index.php/visiondefuturo/index

URL del Documento: https://visiondefuturo.fce.unam.edu.ar/index.php/visiondefuturo/issue/view/20

ISSN 1668 - 8708 - Versión en Línea

E-mail: revistacientifica@fce.unam.edu.ar
} 
como humano -la capacidad de las personas de la comunidad-, no logra fortalecerse debido a la falta de condiciones para su realización.

La problemática que se plantea a partir de la observación del caso, es que actualmente la comunidad no siente el apoyo necesario por parte del municipio en cuanto a la continuidad del desarrollo del Parque. Las visitas se encuentran in crescendo, pero las condiciones del emprendimiento no están aptas para la cantidad de los visitantes que acceden. Es por eso que existe una necesidad inminente y explicita de mejora. Sin embargo, la única respuesta ofrecida por el municipio es la tercerización del emprendimiento, hecho que no sólo dejaría a la comunidad sin sustento económico, sino que, aislada nuevamente del resto de la sociedad.

Para la mejor comprensión de la situación enunciada, a continuación se diversifican las problemáticas observadas en los siguientes escenarios:

- Escenario económico: el lucro que puedan obtener a partir del Parque no es el primer objetivo de la comunidad. La misma considera que debería modificarse la gestión para emplear una organización más empresarial que pueda generar mayores ingresos al Parque. La falta de organización tampoco permite administrar y aprovechar la rentabilidad del emprendimiento. Por ejemplo, el registro de los visitantes es a través de un Excel, en donde solo poseen información de los esquiadores pero no así de los pases diarios o de la gente que solo va de visita durante el día.

- Escenario social: si bien, con el transcurso de los años, la comunidad pudo lograr la integración con el resto de los residentes del lugar -además de haber sido el Parque la consecuencia del desarrollo turístico de la Villa y la llegada de nuevos emprendedores- no poseen al momento convenios con agencias de viaje o promoción de su oferta en los alojamientos de la zona.

- Escenario ambiental: algunas personas de la comunidad no están de acuerdo con el Parque debido a que el mismo desarrolla un "turismo invasivo" que acarrea, como primera consecuencia, la contaminación del lugar con los residuos que dejan. Se debe tener en cuenta que la comunidad tiene muy arraigado el sentimiento del lugar, ya que, consideran que por esas tierras han caminado sus antepasados, y consideran que deben ser cuidadas, de tal forma, que puedan ser disfrutadas por las generaciones futuras.

- Escenario político: si bien el Estado ha brindado su apoyo para el desarrollo del Parque, las inversiones que deben realizar en este tipo de emprendimientos son considerables y continuas (por ejemplo, para ampliar y mantener los medios de elevación), y los ingresos del Parque no son suficientes. A su vez, desde la municipalidad han recibido la propuesta de alquilar las tierras para que un tercero/privado pueda continuar con el emprendimiento, hecho que hace sentir a la comunidad "desplazada", ya que al fin y al cabo, 
este Parque no sólo es un sustento para la comunidad sino una forma de manifestar su identidad como tal.

\begin{abstract}
"A nosotros nos vendría muy bien que alguien nos ayude a reorganizarnos como emprendimiento, necesitamos la ayuda de alguna universidad o de alguien que nos pueda dar una mano a nivel organizativo y a nivel gestión nos vendría muy bien [...]"
\end{abstract}

(Antonio Puel, comunicación personal, febrero 2020)

\title{
Metodología
}

El diseño utilizado, se define como una metodología mixta, ya que se combina el enfoque cuantitativo y cualitativo de investigación en la consulta de fuentes primarias. Respecto al primero se ha recurrido al contacto con la Subsecretaría de Turismo de la Provincia del Neuquén quien ha proporcionado información estadística de la oferta y la demanda de la localidad. Para el enfoque cualitativo se ha contado con la participación de Antonio Aníbal Puel-tesorero de la Comunidad Mapuche Puel- mediante una entrevista telefónica realizada el 13 de febrero del presente año.

Por último, también se han consultado fuentes secundarias de investigación tales como investigaciones previas y artículos periodísticos para una complementación eficiente del desarrollo de la presente investigación.

\section{Marco teórico}

El turismo comunitario se plantea desde sus orígenes, como una alternativa al turismo tradicional. Sus primeras expresiones podemos ubicarlas en Argentina, en los últimos años del siglo XX. Se caracteriza especialmente por su forma de organización, dado que su planificación se proyecta como un modelo de autogestión, que promueve un enfoque participativo y sostenible respecto de los recursos con los que las comunidades cuentan y del uso que de los mismos realizan en sus territorios.

Específicamente en la República Argentina, en el año 2005 se promulgó la Ley Nacional de Turismo ( $\mathrm{N}^{\circ}$ 25.997), la cual destaca en su segundo artículo los principios rectores de la ley, entre los que se encuentra el desarrollo social, económico y cultural: "El turismo es un derecho social y económico de las personas dada su contribución al desarrollo integral en el aprovechamiento del tiempo libre y en la revalorización de la identidad cultural de las comunidades". En efecto, en el 2008 y debido al creciente aumento de la actividad turística desde las comunidades de pueblos originarios el Ministerio de Turismo (MINTUR) propuso el proyecto Red Federal de Turismo Rural Comunitario, actualmente conocido como Red Argentina de Turismo Rural Comunitario (RATuRC). De esta forma, la Red se presenta con el 
objetivo de promover el desarrollo local comunitario y el fortalecimiento de pueblos originarios y sus descendientes, residentes en espacios rurales, mediante el desarrollo de la actividad turística sustentable (Proyecto Red Federal de Turismo Comunitario en ámbitos rurales, 2008, p. 5)

\section{Análisis del caso}

\section{Ubicación geográfica}

El cerro se encuentra localizado en el Departamento de Aluminé, en la provincia de Neuquén en el lado argentino (a $370 \mathrm{kms}$ de la ciudad capital -Neuquén- y a 8 kms de la localidad de Villa Pehuenia) y en la provincia de Malleco en la IX Región de la Araucanía en el lado chileno (a $135 \mathrm{~km}$ de la ciudad capital regional, Temuco). Para llegar desde la ciudad de Neuquén, se debe tomar la ruta nacional 22 hasta la ciudad de Zapala. Luego se debe tomar la ruta provincial 13 por Primeros Pinos en dirección a Villa Pehuenia. Desde allí se recorren 118 km, 50 por camino pavimentado y el resto por ripio consolidado. Luego, para llegar al cerro se deberán recorrer 8 km más por la misma ruta provincial 13 hasta encontrase con el camino de acceso al Batea Mahuida.
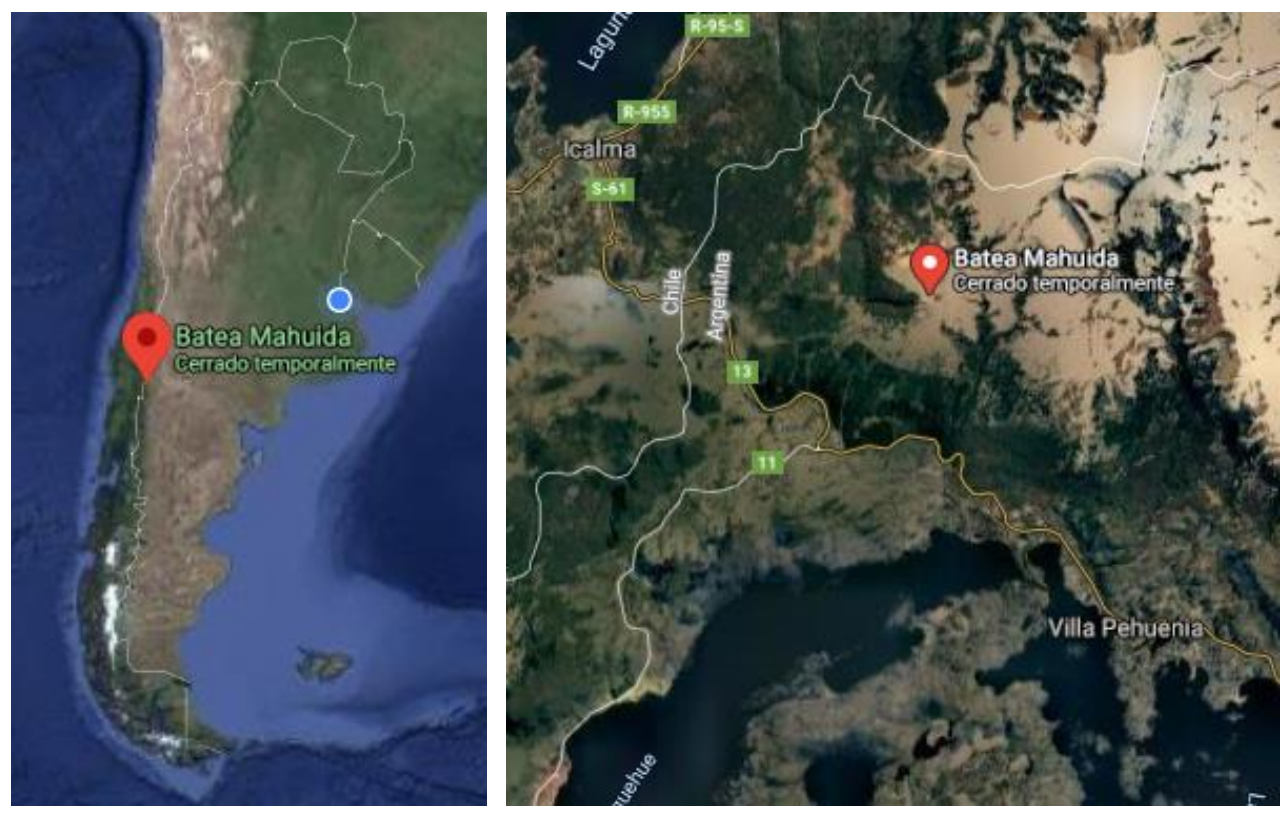

Figura №1: Mapa de localización Parque de Nieve-Batea Mahuida Fuente: print screen de Google Maps, julio 2020.

\section{Historia del Pueblo Mapuche}

La historia del pueblo mapuche, -mapu: tierra, che: gente-, a partir del siglo XV, es una historia de lucha, esclavitud y huida por la supervivencia. Su origen los vincula con los

\footnotetext{
"Visión de Futuro" Año 18, Volumen No 25 N 2, Edición Especial-III Congreso Regional de Economía del Norte Grande-Pág 56-79 URL de la Revista: http://visiondefuturo.fce.unam.edu.ar/index.php/visiondefuturo/index

URL del Documento: https://visiondefuturo.fce.unam.edu.ar/index.php/visiondefuturo/issue/view/20

ISSN 1668 - 8708 - Versión en Línea

E-mail: revistacientifica@fce.unam.edu.ar
} 
araucanos, indígenas establecidos en lo que fue posteriormente el margen oriental de la cordillera, en el actual país de Chile.

Se cree que fue el pueblo más aguerrido y el más difícil de derrotar de toda América. En la Argentina, el pueblo mapuche se encontraba establecido en varias provincias, siendo en total alrededor de 70 a 90 mil personas. Sin embargo, la mayoría se encontraba distribuido en la provincia de Neuquén (junto con parte de Río Negro), donde había alrededor de 30 mil habitantes.

A partir del año 1878 se dan varias embestidas contra los mapuches, incluyendo la famosa "Conquista del Desierto" a cargo de J. A. Roca (que durará hasta los años 1883, cuando se logra la "pacificación" e incorporación de Neuquén al territorio nacional). Es a partir de este hecho que algunas tribus se rinden y otras se desplazan a Chile. Otros dos combates importantes que se llevaron a cabo a pocos kilómetros de donde se encuentra la Villa hoy son los de: "Pulmary" y "Pino Hachado".

Por otro lado, la zona en la que se ubica Villa Pehuenia actualmente, era el lugar histórico de veranada de las comunidades. Es recién a fines del siglo XIX, que se instala definitivamente en el lugar la Comunidad Mapuche Puel (siendo éstos los descendientes de aquellos que habían huido a Chile y luego volvieron a su lugar de origen). Actualmente la comunidad Puel se encuentra en los alrededores del volcán Batea Mahuida y en la angostura de los lagos Aluminé y Moquehue. Mientras que la Comunidad Mapuche Placido Puel se ubica sobre la costa del lago Aluminé y la Catalán se ubica en las afueras de la Villa.

\section{Surgimiento del parque de nieve}

Hasta hace 50 años, en la actual zona de Villa Pehuenia vivían solo los mapuches. El único sustento económico que tenían era la cría de ganado y la elaboración de artesanías. No había luz, agua corriente, ni gas. Tampoco existía la actual ruta 13 que ahora atraviesa la localidad y se conecta luego de $11 \mathrm{~km}$, con un paso fronterizo. Los inviernos eran muy crudos y la nieve un gran inconveniente, ya que de no arrear a los animales, estos perecían. Así fue su forma de supervivencia desde la finalización de la Conquista del Desierto. Gran parte de la comunidad solía irse al "Alto Valle" (provincia de Rio Negro) a buscar trabajo en la cosecha cuando todavía no existía la Villa ni, por supuesto, el Parque de Nieve.

El primer cambio importante en sus expectativas de vida lo tuvieron cuando el Gobierno provincial comenzó a desarrollar la Villa Turística de Villa Pehuenia. Sin embargo, la comunidad observaba "el progreso" desde la margen opuesta de la ruta provincial №23. Más allá de numerosos litigios por tierras y el uso de cursos de agua, que marcaron la incursión del Gobierno en la zona, muchos mapuches comenzaron a cruzar la ruta. Los hombres se

\footnotetext{
“Visión de Futuro" Año 18, Volumen No 25 N², Edición Especial-III Congreso Regional de Economía del Norte Grande-Pág 56-79 URL de la Revista: http://visiondefuturo.fce.unam.edu.ar/index.php/visiondefuturo/index

URL del Documento: https://visiondefuturo.fce.unam.edu.ar/index.php/visiondefuturo/issue/view/20

ISSN 1668 - 8708 - Versión en Línea

E-mail: revistacientifica@fce.unam.edu.ar
} 
emplearon en la construcción, mientras que las mujeres se desarrollaban como empleadas domésticas, mucamas y cocineras en los hoteles. Luego de varios años comenzaron a trabajar en el vivero provincial y las empresas de servicios.

En la actualidad, la agrupación mapuche Puel conserva una posesión de 14.400 hectáreas de acuerdo con un decreto de 1964 que establece la figura de "reserva de tierras" a favor de la agrupación. Con el paso de los años y como consecuencia de las ocupaciones de lotes, el riesgo de que la comunidad comenzara a ver recortado su territorio se acrecentaba. Es Vicente, -último mapuche nombrado cacique por un fallo hereditario- quien comienza los reclamos por usurpación de tierras, ante la gobernación. En 1984, obtiene la personería jurídica de la comunidad en la escrituración de tierras y en el acta oficial. Ese acuerdo, firmado entre el gobernador Felipe Sapag y Vicente, es la partida de nacimiento de Villa Pehuenia. Sin embargo, desafecta de la reserva Puel muchos de los lotes que estaban entre la ruta 13 y el lago Aluminé. Esa porción de tierra representaba menos del 10\% de las 14.400 hectáreas que poseían los mapuches. Como contrapartida, Sapag se comprometió a transformar esos lotes en una aldea turística. Es a partir de allí que la villa turística se gestó y llegaron las oportunidades. Entre otras, la idea de José María Puel (cacique y nieto del fundador de la comunidad) de construir un parque de nieve. El coronel (R) Abel Balda, antártico, experto andinista e instructor de esquí, quien fuera el creador del Centro de esquí de Caviahue por intermedio de la firma Parque Caviahue S.A,y del Parque de Nieve Cerro Wayle, es quien a solicitud de los mapuches proyectó y asesoró a la comunidad en la creación de este Parque de Nieve.

A su vez, el gobierno de Sapag les asignó 70.000 pesos y con ese dinero compraron 100 juegos de esquí, botas y equipos. También montaron un sistema de elevación de unos 300 metros. Desde 1999, se trabajó muy arduamente en la creación de la confitería. La misma se levantó con cantoneras, nylon y machimbres. Además, se construyó una enfermería, un sitio de alquiler de equipos y otras dependencias. A partir de estas transformaciones, el Parque logró su inauguración en julio del año 2000 con una modesta infraestructura pero bajo el insuperable lema de ser el único en el mundo que pertenece a una comunidad indígena y además es administrado por ella. Por último, el gobierno siguiente asistió con materiales para terminar la confitería y el local de alquiler de equipos y a su vez la comunidad participante fue preparada y capacitada por las empresas proveedoras de los equipos. Por otra parte, los mozos y cocineros se entrenaron en un moderno hotel de Aluminé.

Era el deseo de la comunidad superarse y realizar otras actividades además de la cría de ganado. Sin embargo, dada la tensión latente entre los miembros de la comunidad y el resto de la población por la posesión de tierras, la desconfianza del pueblo mapuche respecto 
de las intenciones del gobierno nunca cesó. No obstante, los Puel y los nuevos habitantes de Villa Pehuenia (que fueron llegando con nuevos emprendimientos turísticos a partir del éxito del Parque) alcanzaron una importante integración. Y, sin lugar a dudas, fue el Parque de Nieve lo que produjo un sustento económico importante para la comunidad y, al mismo tiempo, forzó una sociedad comercial entre los Puel y el resto de la Villa, que vive de la hotelería, la gastronomía y las actividades turísticas.

Actualmente, los puestos dentro del Parque van desde instructores de esquí/snowboard hasta empleados de la confitería, locales de alquiler de equipos y puestos de artesanías. En cuanto a las ganancias, el esquema es tipo cooperativa, es decir, que toda la comunidad consigue un ingreso general.

Los instructores mapuches se encargan de enseñar el arte de deslizarse sobre dos tablas por las pistas que vienen preparando desde el año 2000. Esta iniciativa dio trabajo a muchos jóvenes de la comunidad; los más grandes ayudan, empujan y colaboran, pero son los niños y jóvenes los más entusiasmados con transformar a Batea Mahuida en un centro turístico recreativo que funcione durante todo el año.

En los últimos 15 años la mayoría dejó de trabajar con el ganado, dejando los animales sólo para la alimentación de la familia y manteniendo la actividad artesanal. Actualmente en la Villa cerca de 300 personas son empleados del Estado. La mayoría son mapuches y desarrollan sus tareas en el centro de salud, las escuelas, el vivero municipal, el Ente provincial de Energía, vialidad provincial, prefectura, gendarmería y la policía provincial. Son el motor de los servicios públicos de la Villa.

Actualmente el parque da a conocer su historia y su servicio a través de una web oficial con el slogan "Vivir la nieve" y el siguiente logotipo:

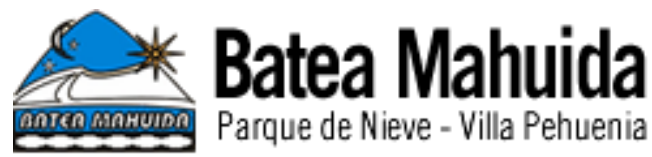

Figura $N^{\circ}$ 2: Logotipo del Parque de Nieve Batea Mahuida

Fuente: Sitio oficial Batea Mahuida-Parque de Nieve-Villa Pehuenia. (s.f.). Consultado en mayo de 2020

\section{Relevamiento estadístico de la localidad de Villa Pehuenia}

Podemos observar que al año 2019 (último dato disponible) la localidad poseía una capacidad total para 1.326 personas en establecimientos turísticos habilitados. Mientras que en el año 2010 solo contaba con 761 plazas. Es decir que en el trascurso de esos 9 años, la Villa ha logrado casi duplicar sus plazas ofrecidas demostrando así un crecimiento en su oferta del $74 \%$. A su vez, en la temporada estival 2019 , la localidad cerró su ocupación en un $82,05 \%$ en plazas y con un acumulado de 60.927 pernoctes, con niveles superiores respecto a otras "Visión de Futuro" Año 18, Volumen N²5 N², Edición Especial-III Congreso Regional de Economía del Norte Grande-Pág 56-79 URL de la Revista: http://visiondefuturo.fce.unam.edu.ar/index.php/visiondefuturo/index URL del Documento: https://visiondefuturo.fce.unam.edu.ar/index.php/visiondefuturo/issue/view/20 
temporadas. También el factor de ocupación ${ }^{1}$ en plazas aumentó en 5,30 puntos comparado al año anterior y los pernoctes en $11,18 \%$, correspondiendo a unas 6.128 camas/noches más. Porcentajes significativos respecto a las demás localidades. ${ }^{2}$

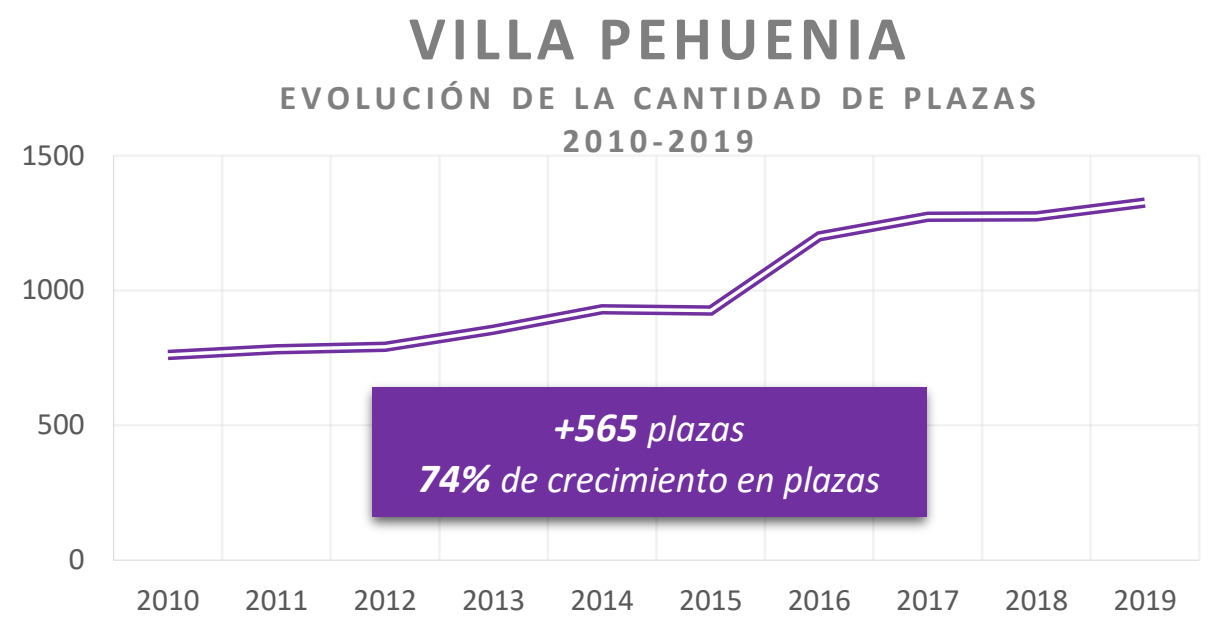

Figura N³: Evolución de la cantidad de plazas años 2010-2019

Fuente: Elaboración propia en base a estadísticas de la Subsecretaría de Turismo de la Provincia del Neuquén.

En cuanto a la demanda turística se ha estudiado el perfil de los turistas para advertir que en el año 2008 más del 96\% de los mismos tenían como objetivo de visita la práctica de actividades invernales obteniéndose así, un crecimiento de 27 puntos porcentuales en comparación al año 2004, donde cerca del 70\% de los visitantes tenían el mismo objetivo. Este no es un dato menor, dado que evidencia que existe un porcentaje de la población que visita la localidad con el interés específico de interactuar con la comunidad mapuche, demostrando de este modo, la creciente visibilidad de esta última. Si bien este porcentaje ha decrecido entre los años 2004 y 2008, ese cambio no se considera significativo, por el contrario, se observa que esto demuestra el continuo interés por la comunidad.

\footnotetext{
${ }^{1}$ Relación en porcentaje entre el total de plazas ocupadas y el total de plazas disponibles en el período de referencia.

${ }^{2}$ Ampliar información en Anexo 1

"Visión de Futuro" Año 18, Volumen No 25 № 2, Edición Especial-III Congreso Regional de Economía del Norte Grande-Pág 56-79 URL de la Revista: $\underline{\text { http://visiondefuturo.fce.unam.edu.ar/index.php/visiondefuturo/index }}$

URL del Documento: https://visiondefuturo.fce.unam.edu.ar/index.php/visiondefuturo/issue/view/20

ISSN 1668 - 8708 - Versión en Línea

E-mail: revistacientifica@fce.unam.edu.ar
} 
PRACTICAR ACTIVIDADES

INVERNALES

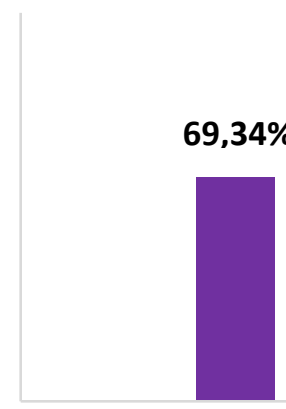

2004

\section{$96,10 \%$}

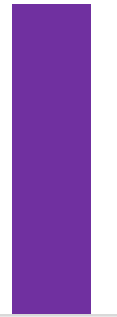

2008
INTERÉS EN COMUNIDAD MAPUCHE

$7,30 \%$

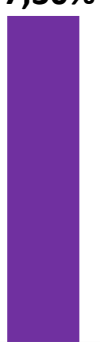

2004
$6,01 \%$

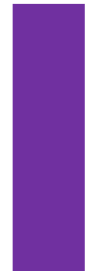

2008

Figura N ${ }^{\circ}$ : Perfil de la demanda turística del Parque de Nieve año 2004 vs 2008

Fuente: Elaboración propia en base a estadísticas de la Subsecretaría de Turismo de la Provincia del Neuquén.

Respeto al origen de los turistas se evidencia que la demanda de la localidad de Villa Pehuenia durante el año 2004 se encontraba compuesta casi en su totalidad por residentes nacionales $(98,06 \%)$, mientras que solo el 1,92\% provenían de otros países, dentro de los cuales, Chile ocupaba el 1,26\%.

En ese mismo año, aproximadamente la mitad de los turistas provenían de la provincia de Buenos Aires. El 32,46\% eran aledaños, es decir, de otras localidades de Neuquén y visitantes de la provincia vecina de Rio Negro. Mientras que el $9 \%$ procedían del resto de las provincias.

Analizando luego los datos obtenidos del año 2008 (último dato disponible), se examina que si bien los porcentajes no variaron significativamente, a diferencia del año 2004, se suman visitantes de las provincias de Santa Fe y Córdoba (12\% y $11 \%$ respectivamente). Por otra parte se observa una disminución de turistas de las provincias de Buenos Aires, Neuquén y Rio Negro. ${ }^{3}$

${ }^{3}$ Ampliar información en Anexo 2

"Visión de Futuro" Año 18, Volumen No 25 № 2, Edición Especial-III Congreso Regional de Economía del Norte Grande-Pág 56-79 URL de la Revista: $\underline{\text { http://visiondefuturo.fce.unam.edu.ar/index.php/visiondefuturo/index }}$

URL del Documento: https://visiondefuturo.fce.unam.edu.ar/index.php/visiondefuturo/issue/view/20

ISSN 1668 - 8708 - Versión en Línea

E-mail: revistacientifica@fce.unam.edu.ar 


\section{ORIGEN DE LOS TURISTAS-AÑO 2004-}
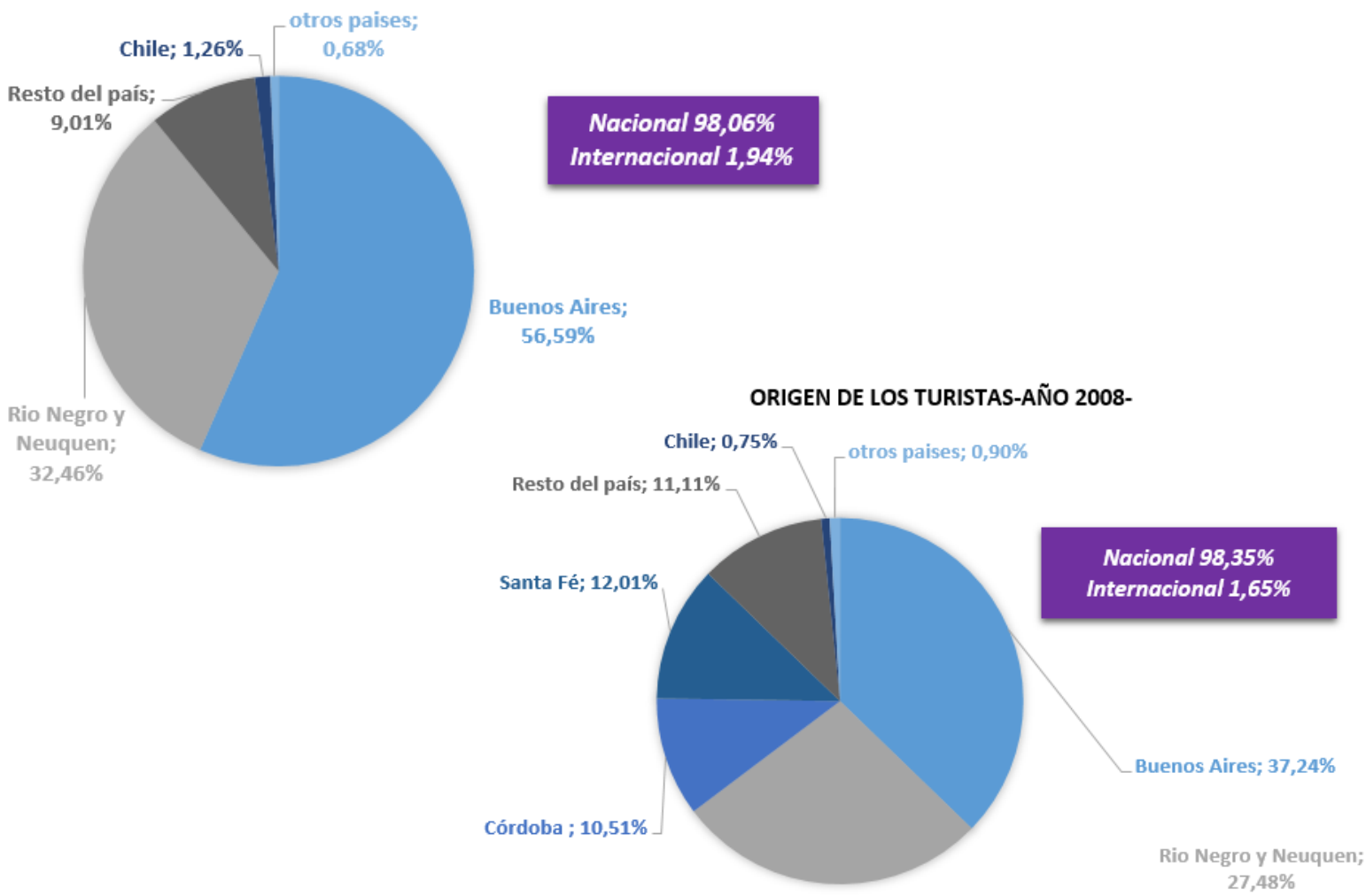

Figura N5: Origen de los visitantes del Parque de Nieve año 2004 vs 2008

Fuente: Elaboración propia en base a estadísticas de la Subsecretaría de Turismo de la Provincia del Neuquén.

\section{Relevamiento cualitativo de la Comunidad Mapuche Puel}

- A partir de la entrevista telefónica realizada a Antonio Aníbal Puel (miembro y tesorero de la comunidad) se obtuvo, en resumen, la siguiente información4:

- La comunidad está compuesta por 250 familias aproximadamente y está reglamentada como "asociación civil sin fines de lucro agrupación Mapuche Puel". Tiene un estatuto que establece un mecanismo de asambleas y todos los cargos que se poseen dentro de la comunidad. El desarrollo de la asociación fue mejorando con los años, ya que antes los roles eran más autoritarios y hoy eligen discutir todas las problemáticas en dichas asambleas logrando el consenso de toda la comunidad.

- La idea de desarrollar el Parque fue el objetivo y anhelo de la comunidad de hacer algo más que criar animales y vender artesanías y, a su vez, poder brindarles un futuro a los jóvenes. Comenzó con una pequeña confitería de cartonera (madera muy económica). Contaba con una pista armada y se daban clases de esquí pero sin disponer con la ropa

${ }^{4}$ Formato base de entrevista en Anexo 3

"Visión de Futuro" Año 18, Volumen No 25 № 2, Edición Especial-III Congreso Regional de Economía del Norte Grande-Pág 56-79 URL de la Revista: http://visiondefuturo.fce.unam.edu.ar/index.php/visiondefuturo/index

URL del Documento: https://visiondefuturo.fce.unam.edu.ar/index.php/visiondefuturo/issue/view/20

ISSN 1668 - 8708 - Versión en Línea

E-mail: revistacientifica@fce.unam.edu.ar 
adecuada para este deporte. A su vez, el único medio de elevación era un Poma chico (medio de elevación de arrastre para principiantes). A partir de la consulta realizada al entrevistado acerca de si cuando surge la idea del Parque, contaron con el apoyo de la municipalidad, éste responde afirmando que tuvieron el sostén del estado, aunque requerían y esperaban uno de mayor magnitud.

"Era un cambio rotundo no sólo para la comunidad Puel sino también para el resto de la población tanto de Pehuenia como de Moquehue porque le dio un impulso enorme a la actividad turística invernal. Hasta ese tiempo la única temporada era estival y en invierno no había nada, entonces a partir del Parque de nieve surge la actividad turística en invierno y además le da una nueva oportunidad a los emprendedores de Pehuenia que no pertenecían a la comunidad [...]"

(Antonio Puel, comunicación personal, febrero 2020)

- El desarrollo del Parque fue lento ya que consideran que, al día de hoy, aun no se encuentran organizados de la forma adecuada. El Parque no tiene un objetivo empresarial desde la comunidad (el entrevistado se refiere a que el mayor objetivo no es sacar la mayor ganancia). A su vez, una de las intenciones del Parque era que los jóvenes no tengan que irse de la localidad en busca de un futuro, sin embargo, esta situación generó que los jóvenes dejen de capacitarse por ya contar con un ingreso de dinero para su sustento.

- Actualmente la estructura del parque se compone del servicio de confitería, servicio de rental de ski, la escuela de esquí y escuela de snowboard y una zona de trineos. Respecto a las pistas siguen siendo las mismas. Han ampliado sus medios de elevación (3 pomas chicos, un t-bar y un reciente teleski) y respecto a la asignación de roles dentro del emprendimiento se observa que los únicos puestos fijos son los de instructores de esquí mientras que los demás (personal administrativo, confitería, medios de elevación) son rotativos.

- Respecto a la temporada estival, el parque se encuentra abierto pero sin ninguna actividad, solo se cobra un pase de acceso, que se utiliza para el mantenimiento del cerro (recolección de residuos). La pasada temporada estival (2020) pensaban abrir las instalaciones pero no pudieron hacerlo, debido a las reparaciones que no se lograron completar (cocina y salubridad del ambiente).

\section{Propuesta para la potencialización del turismo comunitario de Villa Pehuenia}

\section{Áreas de Actuación}

Para comenzar con el desarrollo de la propuesta primero se ha utilizado la metodología de Llorca y Bueno a fin de identificar tres grandes áreas de actuación en política turística (Llorca, Gallego J., Bueno Pedro, A.,s.f):

\footnotetext{
"Visión de Futuro" Año 18, Volumen No 25 N 2, Edición Especial-III Congreso Regional de Economía del Norte Grande-Pág 56-79 URL de la Revista: http://visiondefuturo.fce.unam.edu.ar/index.php/visiondefuturo/index

URL del Documento: https://visiondefuturo.fce.unam.edu.ar/index.php/visiondefuturo/issue/view/20

ISSN 1668 - 8708 - Versión en Línea

E-mail: revistacientifica@fce.unam.edu.ar
} 
A. Producto: determinar cuáles serán las acciones necesarias para mejorar el producto turístico existente, en este caso, el Parque de Nieve.

B. Comercialización: establecer, a partir de la mejora de la oferta del Parque, los mecanismos necesarios para poder ampliar la publicidad del mismo, ya que al momento, no cuentan con folletería, ni convenios con agencias turísticas.

C. Entorno: crear las actuaciones necesarias para intentar reducir los impactos negativos de la actividad turística en el entorno (principalmente residuos generados por los turistas que impactan en la contaminación del Parque)

A partir de esto, se elabora una propuesta de objetivos específicos que consideran los efectos económicos, sociales y medioambientales del turismo a fin de lograr un perfeccionamiento y mejora del producto existente en el marco de un programa para un turismo más sostenible.

Para ello, se ha seleccionado la metodología desarrollada en el Programa de las Naciones Unidas para el Medio Ambiente y la Organización Mundial del Turismo (PNUMA \&OMT, 2006) que clasifican a dichos objetivos dentro de los siguientes apartados:

1) Viabilidad económica: potenciar el producto ofrecido, en este caso, el Parque de Nieve, conociendo previamente las necesidades de la demanda, identificar qué es lo que buscan para adaptarlo al producto actual con el fin de lograr el retorno de los visitantes. A su vez, generar un producto de calidad para la temporada estival que permita el continuamiento de los ingresos durante todo el año y así obtener beneficios a largo plazo. Por último, buscar intensificar la promoción del emprendimiento y dar a conocer la particularidad identitaria de la Comunidad Mapuche, logrando así, no sólo una experiencia diferente para el visitante sino también el posicionamiento como centro invernal respecto a los demás centros de la provincia.

2) Prosperidad local: lograr una mejora en la organización de los ingresos. Determinar a través de porcentajes cuáles se retribuirán a la comunidad local y cuáles se destinarán al mantenimiento y mejora del Parque, evitando de esta forma una fuga o mala administración de lo recaudado.

Diversificar la oferta generando convenios con alojamientos, agencias de viaje u otros negocios, logrando así más provecho para ellas y, a su vez, aumentar los segmentos de mercado que lleguen al Parque. Mejorar el servicio de cafetería y la venta de artesanías de la comunidad dentro del Parque.

3) Calidad de empleo: generar la igualdad de oportunidades para todos los miembros de la comunidad. Designar roles fijos que permitan que cada empleado del Parque se sienta identificado con su puesto, logrando así una mayor eficacia y productividad del mismo. Hacer

\footnotetext{
“Visión de Futuro" Año 18, Volumen N²5 N², Edición Especial-III Congreso Regional de Economía del Norte Grande-Pág 56-79 URL de la Revista: http://visiondefuturo.fce.unam.edu.ar/index.php/visiondefuturo/index

URL del Documento: https://visiondefuturo.fce.unam.edu.ar/index.php/visiondefuturo/issue/view/20

ISSN 1668 - 8708 - Versión en Línea

E-mail: revistacientifica@fce.unam.edu.ar
} 
hincapié en el perfeccionamiento de las tareas a través de capacitaciones y formaciones que permitan el aprendizaje continuo.

4) Satisfacción del visitante: destacar dentro del producto la importancia del entorno, ofreciéndolo como una experiencia diferente, enmarcándolo, por ejemplo, a través de: "la combinación de un atractivo del medio ambiente natural con la cultura local". De esta forma, dar a conocer la cultura mapuche y la importancia que le genera a ésta el cuidado del medioambiente, permitirá demostrar la intención de la comunidad de preservar el lugar para el disfrute de las generaciones futuras. Por otra parte, evitar el malestar de los visitantes que se acumulan en los medios de elevación, organizándolos por ejemplo, a través de grupos y adaptar las instalaciones, de forma tal, que aseguren el acceso de personas discapacitadas.

5) Control local: garantizar a la comunidad su participación dentro de las decisiones de la localidad. Asegurar el cumplimiento de la "consulta previa, libre e informada"5, que es un derecho de la comunidad. Afianzar los vínculos entre la comunidad y los actores políticos, a fin de, generar la confianza mutua y la prosperidad de ambas partes.

6) Bienestar de la comunidad: generar un equilibrio entre el emprendimiento y la cultura local. Por ejemplo, regulando la cantidad de visitas o mejorando la administración de las mismas, a fin de evitar el turismo invasivo con impacto negativo en el ambiente, ya sea con residuos o con la irrupción al resto de la comunidad Mapuche ajena al emprendimiento. Incluir la utilización de señalética o reglamentaciones con carteles que concienticen y regulen el comportamiento del visitante.

7) Riqueza cultural: resguardar el valor simbólico y ambiental del cerro. Trabajar la comunicación con los visitantes invitando a los mismos a conocer la historia, la cultura y las tradiciones del pueblo Mapuche. Esta acción ofrecería un valor más significativo a la visita de los turistas y permitiría infundir en la comunidad la importancia de transmitir a los visitantes el hecho de que el emprendimiento fue el resultado del anhelo y la lucha de una comunidad indígena que logró alcanzar su objetivo. De esta forma, ganarían no sólo el respeto y la compresión de la comunidad receptora sino también el sentido de identidad de la comunidad respecto del emprendimiento.

8) Diversidad biológica: mantener buenas normas de conservación de la zona para que el impacto del turismo no afecte a la protección de araucarias, especie milenaria que durante siglos alimentó y protegió a los descendientes de los pueblos de esta área. Brindar la información adecuada a la llegada de los visitantes y evaluar la posibilidad de declarar la

\footnotetext{
${ }^{5}$ La consulta es un derecho de los pueblos indígenas reconocido tanto en el marco jurídico internacional como en el nacional en donde los gobiernos deben consultar a los pueblos indígenas sobre medidas legislativas o administrativas que puedan afectar su calidad de vida.

"Visión de Futuro" Año 18, Volumen No 25 № 2, Edición Especial-III Congreso Regional de Economía del Norte Grande-Pág 56-79 URL de la Revista: http://visiondefuturo.fce.unam.edu.ar/index.php/visiondefuturo/index

URL del Documento: https://visiondefuturo.fce.unam.edu.ar/index.php/visiondefuturo/issue/view/20

ISSN 1668 - 8708 - Versión en Línea

E-mail: revistacientifica@fce.unam.edu.ar
} 
región como "área protegida" o generar estrategias de turismo sostenible o ecoturismo. A su vez promover una actividad educativa o códigos de conducta para los visitantes con la finalidad del cuidado de las tierras y las condiciones del cerro. Mantener las particularidades únicas del lugar y la calidad del paisaje y no exigirle más de lo que provee naturalmente.

9) Pureza medioambiental: administrar de forma eficiente la utilización de recursos del Parque e incentivar las campañas de reciclaje y reutilización dentro del emprendimiento (especialmente en el servicio de confitería) y para los visitantes. Reducir los residuos generados por los visitantes, como así también, las emisiones perjudiciales para el ambiente a través de los medios de elevación y las aguas cloacales a fin de mantener la salud y la biodiversidad y de esta forma, contribuir a la disminución de la huella de carbono.

\section{Actores}

A continuación se presenta, de forma sintetizada, los actores identificados según la clasificación observada en Llorca y Bueno (Llorca, Gallego J., Bueno Pedro, A.,s.f).

En principio se identificó a los actores principales de la actividad turística por el papel que pueden y deben jugar a la hora de elaborar la política turística, tanto en el sector público como en el sector privado y el sector voluntario.

A su vez se consideró pertinente agregar una función generalizada para cada una de las clasificaciones.

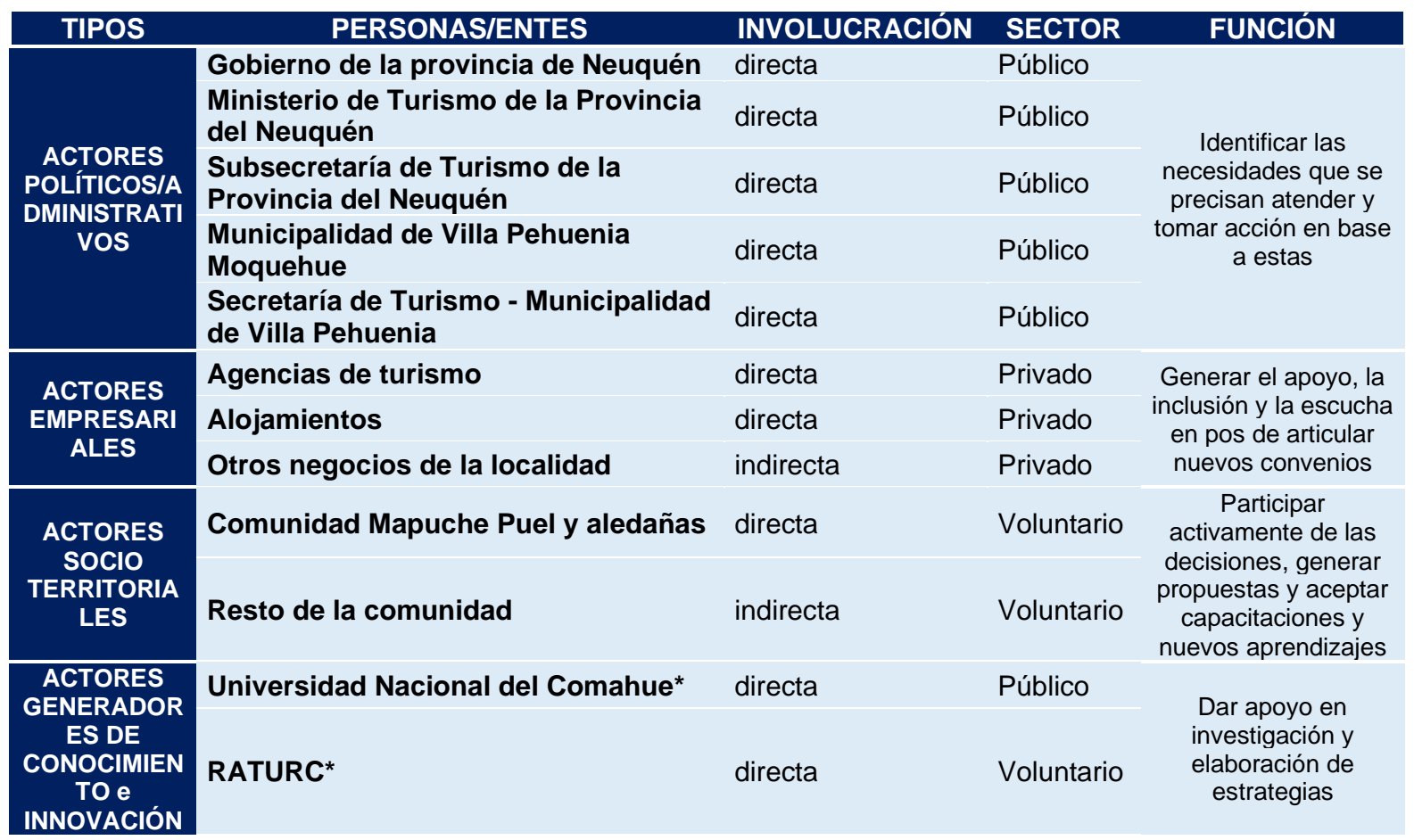

Figura $\mathrm{N}^{\circ}$ 6: Cuadro de actores identificados

Fuente: elaboración propia en base a Llorca, Gallego J., Bueno Pedro, A.,s.f

\footnotetext{
“Visión de Futuro" Año 18, Volumen N²5 N², Edición Especial-III Congreso Regional de Economía del Norte Grande-Pág 56-79 URL de la Revista: http://visiondefuturo.fce.unam.edu.ar/index.php/visiondefuturo/index

URL del Documento: https://visiondefuturo.fce.unam.edu.ar/index.php/visiondefuturo/issue/view/20

ISSN 1668 - 8708 - Versión en Línea

E-mail: revistacientifica@fce.unam.edu.ar
} 
*Se reflexiona acerca de la elección de una Universidad Nacional. A consideración propia de la autora, la Universidad Nacional del Comahue sería un ejemplo pertinente para el caso, ya que trabaja en concordancia con las comunidades originarias de la provincia.

Por otra parte, se considera que la Red Argentina de Turismo Rural Comunitario podría funcionar como mediador o intermediario entre la comunidad y los actores públicos debido a que es una organización social y solidaria que genera autogestión real a las comunidades campesinas y descendientes de pueblos originarios, en el marco de un desarrollo turístico sostenible, bajo los principios del comercio justo.

\section{Instrumentos}

En el presente apartado se procede a brindar una serie de recomendaciones de instrumentos de política pública utilizando la clasificación desarrollada en el Programa de las Naciones Unidas para el Medio Ambiente y la Organización Mundial del Turismo (PNUMA \& OMT, 2006) la cual refiere a instrumentos que pueden ser utilizados a fin de influir en la sostenibilidad de cualquier tipo de turismo, categorizados en los siguientes apartados:

Instrumentos organizativos: colaboraciones a través de un organismo público, ya sea, municipalidad, Secretaría de Turismo de la provincia, universidades, entre otros, que permita desarrollar la potencialidad del emprendimiento, manteniendo las condiciones históricas de la comunidad. Dicha colaboración podría ser desarrollada a través de un servicio de consultoría o estudio de impacto ambiental socioeconómico. Por ejemplo la Universidad Nacional del Comahue, que pertenece a la provincia y tal como lo indica su escudo, se encuentra alineada con la cosmovisión y representación del espacio mapuche.

Instrumentos financieros/ económicos: alianzas con el gobierno municipal y/o provincial que permitan, por ejemplo, obtener una asignación fija de fondos del presupuesto público (ya sea del presupuesto municipal o provincial). La misma ayudaría al mantenimiento de la infraestructura, la inversión en nuevas tecnologías que permitan desarrollar la innovación del Parque, y por último la inversión en cursos especializados que permitan mejorar la formación de los empleados del Parque.

- Instrumentos de comunicación: elaboración de folletería para agencias de viajes, alojamientos y otros negocios. Incorporación de una sección exclusiva de la comunidad mapuche dentro de la oficina de informes turísticos (incluyendo un representante de la comunidad).

- Instrumentos de medición: implementación de un sistema de planificación de actividades y perfeccionamiento del sistema de registro de visitantes. Adquirir algún software o programa de forma tal, que permita información detallada de los turistas (variables como

\footnotetext{
"Visión de Futuro" Año 18, Volumen N²5 N², Edición Especial-III Congreso Regional de Economía del Norte Grande-Pág 56-79 URL de la Revista: http://visiondefuturo.fce.unam.edu.ar/index.php/visiondefuturo/index

URL del Documento: https://visiondefuturo.fce.unam.edu.ar/index.php/visiondefuturo/issue/view/20

ISSN 1668 - 8708 - Versión en Línea

E-mail: revistacientifica@fce.unam.edu.ar
} 
origen, residencia, nivel educativo, edad, gustos y preferencias, nivel socioeconómico, entre otros).

- Instrumentos de mando y control: se considera proponer una participación externa tomando en cuenta la posibilidad de un co-manejo (o manejo compartido) del Parque sin intervenir en las condiciones del título de propiedad de las tierras.

- Instrumentos voluntarios: tener en cuenta las "Directrices para el desarrollo turismo comunitario" elaboradas en 2001 por el Fondo Mundial para la Naturaleza (WWF por sus siglas en ingles) que tienen como propósito suministrar un punto de referencia para el personal que hace trabajo de campo y promover un enfoque coherente, ya que describen algunos principios generales y destacan ciertas observaciones prácticas para el ecoturismo comunitario, o ecoturismo basado en la comunidad.

- Instrumentos de apoyo: por un lado, diversificación de la publicidad del parque a través de campañas de marketing que respeten la cosmovisión que la comunidad quiere expresar. Por otro, realización continuada de capacitaciones a los miembros del parque a fin de fortalecer la formación de los mismos.

- Instrumentos coyunturales: generación de protocolos e información necesaria para dar seguridad y tranquilidad a los turistas que visiten el lugar en el marco de la presente pandemia COVID-19.

\section{CONCLUSIÓN}

Es sustancial destacar que este resumen de recomendaciones que surgen a partir de la elaboración del presente trabajo, incluyen a los actores principales, es decir a los miembros de la comunidad afectados al emprendimiento, a fin de escuchar sus necesidades y hacerlos parte de la toma de decisiones.

Se debería comprender que, hasta hace pocos años los mapuches solo criaban animales. Pero hoy en día se desarrollan no sólo en su propio emprendimiento, sino que muchos de ellos, son empleados del Estado y ejecutan sus tareas en centros de salud, escuelas y otros servicios.

Es destacable que el parque ha generado la inclusión de esta comunidad que fue marginada durante muchos años, pudiendo a través de este emprendimiento propiciar un modelo de desarrollo que promueva la inserción de sus miembros en una actividad que beneficia el crecimiento y desarrollo de toda la localidad de Villa Pehuenia.

Los objetivos de política turística de la presente propuesta son diversos y variados. Aun así, se cree sustancial la consideración de las políticas fiscales y medioambientales que aseguren la continuidad y prosperidad futura del emprendimiento. Sin embargo, es 
fundamental que la comunidad sienta la aceptación y el apoyo de los actores públicos y del resto de la localidad para afianzar su cosmovisión e identidad como comunidad Mapuche.

"La existencia de recursos, atractores y sistemas de apoyo conforma un destino turístico. Sin embargo, la mera existencia de estos elementos no garantiza su permanencia a largo plazo si no es capaz de adaptarse a las condiciones cambiantes del entorno. Podríamos afirmar que las ventajas comparativas ya no son suficientes para mantenerse en el mercado"

(Llorca, Gallego J., Bueno Pedro, A., s.f., p.33) 


\section{ANEXOS}

Anexo 1: Oferta turística: Establecimientos turísticos habilitados

Cuadro N¹: Evolución de la cantidad de plazas años 2010-2019

\begin{tabular}{ccc}
\hline Año & Cantidad & Variación \% \\
\hline 2010 & 761 & - \\
2011 & 782 & $3 \%$ \\
2012 & 792 & $1 \%$ \\
2013 & 854 & $8 \%$ \\
2014 & 931 & $9 \%$ \\
2015 & 925 & $-1 \%$ \\
2016 & 1201 & $30 \%$ \\
2017 & 1274 & $6 \%$ \\
2018 & 1275 & $0 \%$ \\
2019 & 1326 & $4 \%$ \\
\hline Variación & $\mathbf{5 6 5}$ & $\mathbf{7 4 \%}$
\end{tabular}

Fuente: Elaboración propia en base a estadísticas de la Subsecretaría de Turismo de la Provincia del Neuquén.

\section{Anexo 2: Demanda turística. Caracterización de la demanda-Temporada Invernal}

Cuadro $N^{\circ}$ 2: Evolución de indicadores- temporada alta invernal años 2004 vs 2008 (último dato disponible).Año 2004= 274 grupos y 1.032 turistas; Año 2008= 175 grupos y 666 turistas

\begin{tabular}{|c|c|c|c|c|}
\hline & \multirow{2}{*}{ Variable de análisis } & & \multicolumn{2}{|c|}{ Año } \\
\hline & & & 2004 & 2008 \\
\hline \multirow[t]{9}{*}{ ORIGEN } & Nacional & Buenos Aires & $56,59 \%$ & $37,24 \%$ \\
\hline & & $\begin{array}{l}\text { Rio Negro y } \\
\text { Neuquén }\end{array}$ & $32,46 \%$ & $27,48 \%$ \\
\hline & & Córdoba & $0,00 \%$ & $10,51 \%$ \\
\hline & & Santa Fe & $0,00 \%$ & $12,01 \%$ \\
\hline & & Resto del país & $9,01 \%$ & $11,11 \%$ \\
\hline & Total & & $98,06 \%$ & $98,35 \%$ \\
\hline & Internacional & Chile & $1,26 \%$ & $0,75 \%$ \\
\hline & & otros países & $0,68 \%$ & $0,90 \%$ \\
\hline & Total & & $1,94 \%$ & $1,65 \%$ \\
\hline \multirow{3}{*}{$\begin{array}{l}\text { Total } \\
\text { EXPERENCIA } \\
\text { PREVIA EN E } \\
\text { LUGAR }\end{array}$} & & & $100 \%$ & $100 \%$ \\
\hline & Demanda Repetitiva & & $41 \%$ & $50,75 \%$ \\
\hline & Demanda no Repetitiva & & $59 \%$ & $49,25 \%$ \\
\hline Total & & & $100 \%$ & $100 \%$ \\
\hline \multirow[t]{4}{*}{ GRUPO DE VIAJE } & Familias & & $76,64 \%$ & $81,14 \%$ \\
\hline & Parejas & & $16,06 \%$ & $11,43 \%$ \\
\hline & Personas solas & & $2,92 \%$ & $3,43 \%$ \\
\hline & Grupo de amigos & & $4,38 \%$ & $4 \%$ \\
\hline Total & & & $100 \%$ & $100 \%$ \\
\hline MOTIVOS* & $\begin{array}{l}\text { Practicar actividades } \\
\text { invernales }\end{array}$ & & $69,34 \%$ & $96,10 \%$ \\
\hline
\end{tabular}

“Visión de Futuro" Año 18, Volumen N²5 N² 2, Edición Especial-III Congreso Regional de Economía del Norte Grande-Pág 56-79 URL de la Revista: http://visiondefuturo.fce.unam.edu.ar/index.php/visiondefuturo/index

URL del Documento: https://visiondefuturo.fce.unam.edu.ar/index.php/visiondefuturo/issue/view/20

ISSN 1668 - 8708 - Versión en Línea

E-mail: revistacientifica@fce.unam.edu.ar 


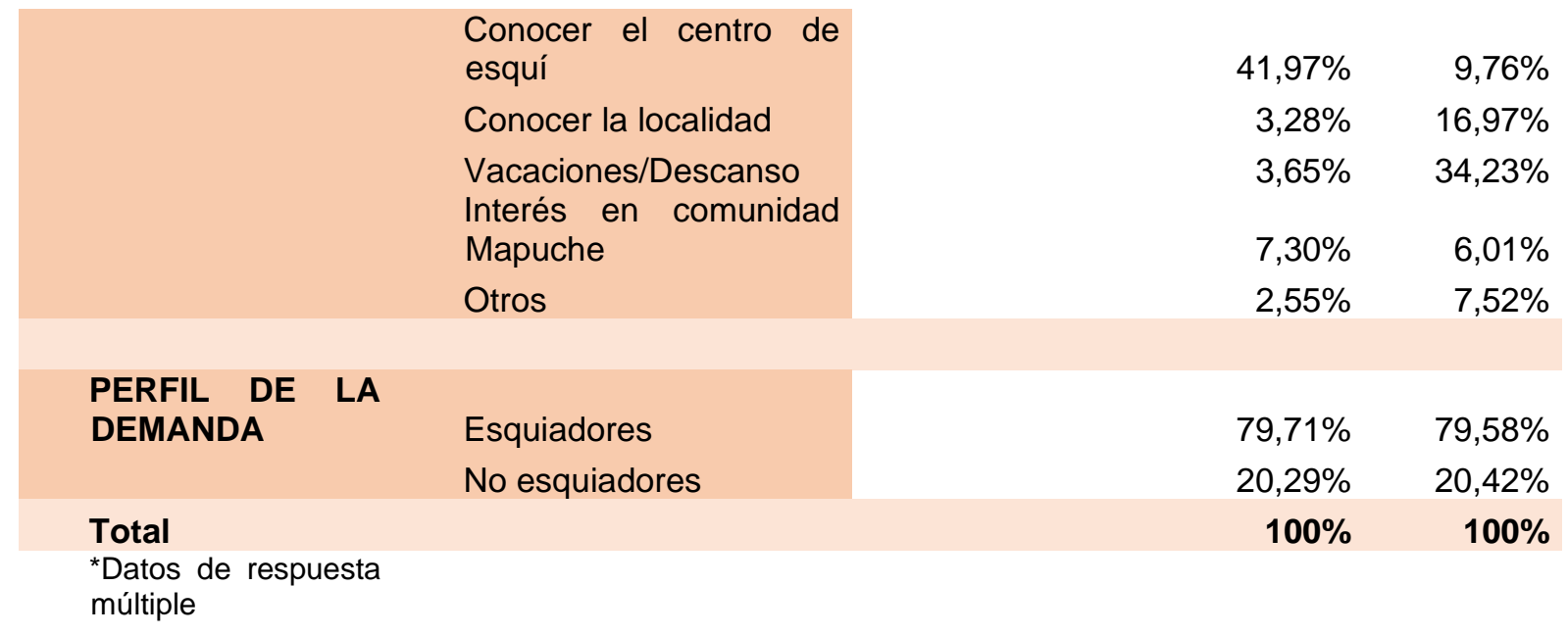

Fuente: Elaboración propia en base a estadísticas de la Subsecretaría de Turismo de la Provincia del Neuquén.

\section{Anexo 3: Punteo de preguntas entrevista Antonio Puel}

1. Presentación del entrevistado y su comunidad

a) Presentación del entrevistado, ¿Quién es? (nombre, a que comunidad pertenece, etcétera)

b) ¿Cuántas familias integran su comunidad?

c) ¿Tienen alguna forma de organización en la comunidad?

d) ¿Qué rol ocupa usted dentro de la comunidad como referente de la actividad turística?

\section{Historia del Parque}

a) ¿Qué los llevo a tener la idea de la creación de un Parque de Nieve?

b) ¿Cuándo y dónde surgió la iniciativa para construir el Parque Recreativo Batea Mahuida?

c) Inconvenientes: ¿Se presentaron dudas, miedos o conflictos internos dentro de la comunidad a la hora de tomar la decisión de desarrollar el parque? ¿Cuáles? ¿Cómo los superaron?

d) Antes de la creación: ¿Cuál era el sustento económico de la comunidad? ¿Y el contacto con el resto de la población?

e) ¿Cómo fue el comienzo del emprendimiento? ¿Tuvieron ayuda de algún organismo externo?

f) ¿Cuál era la infraestructura inicial, actividades y servicios con los que comenzaron?

g) Con el paso de los años, ¿Cómo fueron desarrollándose? ¿Recibieron capacitaciones?

h) ¿Cambió la relación con el resto de la población?

i) ¿Tienen nuevos proyectos?

3. Características de la oferta turística de su comunidad

a) ¿En qué consiste su oferta turística actual en cuanto a actividades y servicios?

b) ¿Cómo es la infraestructura actual? ¿Y el sustento en la temporada estival?

c) ¿Cuántos miembros de la comunidad trabajan en la actividad turística? ¿Qué tareas realiza cada uno?

d) ¿Hay consenso entre todos los miembros de la comunidad respecto de la actividad turística? ¿Todos están de acuerdo?

e) ¿Cómo promocionan su oferta? Los visitantes que reciben ¿Los captan en el destino o antes de que viajen? ¿Cómo? ¿Tienen vínculos con agencias u operadores turísticos?

f) ¿Utilizan algún sistema para el registro de turistas?

g) ¿Qué ideas o deseos les gustaría implementar?

\section{Vínculo con otras organizaciones}

a) ¿Tienen algún vínculo con organismos públicos (ejemplo: secretaria de turismo)? ¿Y con la RATURC?

b) ¿Desde cuándo se relacionan con estas organizaciones? ¿Qué fortalezas y debilidades encuentran en su vínculo con ellos?

c) ¿Cómo se organiza la comunidad de manera interna y externa (es decir con los organismos públicos)? ¿Designan representantes?

\footnotetext{
"Visión de Futuro" Año 18, Volumen No 25 N 2, Edición Especial-III Congreso Regional de Economía del Norte Grande-Pág 56-79 URL de la Revista: http://visiondefuturo.fce.unam.edu.ar/index.php/visiondefuturo/index

URL del Documento: https://visiondefuturo.fce.unam.edu.ar/index.php/visiondefuturo/issue/view/20

ISSN 1668 - 8708 - Versión en Línea

E-mail: revistacientifica@fce.unam.edu.ar
} 
d) En relación con la situación de sus tierras ¿Tienen título de propiedad? ¿Tenencia provisoria? ¿Vínculo con algún organismo del Estado? ¿Con APN? ¿Co-manejo?

\section{REFERENCIAS}

Anuario Estadístico en Turismo-Villa Pehuenia-Moquehue. (2016). Subsecretaria de Turismo Provincia del Neuquén. http://neuquentur.gob.ar/lab/wp-content/uploads/2017/09/F-5VILLA-PEHUENIA-MOQUEHUE-A\%C3\%910-2016.pdf.

Demanda turística real. (2014). Subsecretaria de Turismo Provincia del Neuquén. http://neuquentur.gob.ar/lab/wp-content/uploads/2015/10/B-1-Demanda-turisticaprovincial-2014.pdf.

Drovetto, J. (2016, 4 de septiembre). Batea Mahuida: la pista de esquí ancestral. La Nación. https://www.lanacion.com.ar/lifestyle/batea-mahuida-la-pista-de-esqui-ancestralnid1934670.

El cráter del volcán Batea Mahuida, en Villa Pehuenia. (2010, 10 de enero). La Nación. https://www.lanacion.com.ar/turismo/viajes/el-crater-del-volcan-batea-mahuida-en-villapehuenia-nid1219943.

Fondo Mundial para la Naturaleza. (2001). Directrices para el desarrollo turismo comunitario Forneris, L. (2014). Diagnóstico para el desarrollo del Turismo Rural Comunitario en el Parque Nacional Lanín [tesis de grado, Universidad Nacional del Sur]. Repositorio Institucional UNS

http://repositoriodigital.uns.edu.ar/bitstream/123456789/3220/3/Forneris\%2C\%20Luc\% C3\%ADa.pdf.

Informe centros invernales julio-agosto-septiembre. (2018). Subsecretaria de Turismo Provincia del Neuquén. http://neuquentur.gob.ar/lab/wpcontent/uploads/2018/11/TEMPORADA-INVERNAL-2018-INFORME-FINALJulio-

Agosto-y-Septiembre.pdf.

Informe - temporada alta invernal. (2017). Subsecretaria de Turismo Provincia del Neuquén. http://neuquentur.gob.ar/lab/wp-content/uploads/2018/07/Informe-Temporada-AltaInvernal-Periodo-03-al-30-de-Julio-A\%C3\%B10-2017.pdf.

Informe - temporada alta invernal. (2016). Subsecretaria de Turismo Provincia del Neuquén. http://neuquentur.gob.ar/lab/wp-content/uploads/2018/07/Informe-Temporada-AltaInvernal-Periodo-04-al-31-de-Julio-A\%C3\%B10-2016.pdf.

Informe estadístico final de temporada estival. (2019). Subsecretaria de Turismo Provincia del Neuquén.

Informe centros invernales julio-agosto-septiembre. (2018). Subsecretaria de Turismo Provincia del Neuquén. http://neuquentur.gob.ar/lab/wp-

\footnotetext{
“Visión de Futuro" Año 18, Volumen No 25 № 2, Edición Especial-III Congreso Regional de Economía del Norte Grande-Pág 56-79 URL de la Revista: http://visiondefuturo.fce.unam.edu.ar/index.php/visiondefuturo/index

URL del Documento: https://visiondefuturo.fce.unam.edu.ar/index.php/visiondefuturo/issue/view/20 
content/uploads/2018/11/TEMPORADA-INVERNAL-2018-INFORME-FINALJulio-

Agosto-y-Septiembre.pdf.

Llorca, Gallego J., Bueno Pedro, A. (s.f) La Política Turística. El marco de actuación.

Universidad Abierta de Catalunya.

Mapa Villa Pehuenia (s.f.). En Google Maps. https://www.google.com.ar/maps/

Marenzana, N (2003). Percepción de los impactos sociales y culturales por parte de la comunidad Mapuche Puel - Villa Pehuenia - Aluminé. Universidad Nacional del Comahue.

https://www.researchgate.net/publication/333634976_PERCEPCION_DE_LOS_IMPA CTOS_SOCIALES_Y_CULTURALES_POR_PARTE_DE_LA_COMUNIDAD_MAPUC HE_PUEL_-VILLA_PEHUENIA_-

ALUMINE_Lic_NATALIA_MARENZANA/link/5cf8584892851c4dd02c3bc0/download.

Márquez Pérez, M. (2017). Plan local de fortalecimiento turístico en Ituzaingó, provincia de Corrientes. Dirección Nacional de Inversiones Turísticas.

Monfort Mir, V. (2000). La política turística: una aproximación. Universidad de Murcia, cuaderno de turismo $\mathrm{N}^{\circ} 6$. https://www.redalyc.org/pdf/398/39800601.pdf.

Naciones Unidas. (s.f.).Objetivos de desarrollo sostenible. Consultado en mayo de 2020. https://www.un.org/sustainabledevelopment/es/objetivos-de-desarrollo-sostenible/ Oferta de alojamiento turístico. (2014). Subsecretaria de Turismo Provincia del Neuquén. http://neuquentur.gob.ar/lab/wp-content/uploads/2015/08/A-

1_Oferta_provincial_de_alojamiento_tur--stico_2014.pdf.

Programa de las Naciones Unidas para el Medio Ambiente (PNUMA) y Organización Mundial del Turismo (OMT). (2006). Por un Turismo más Sostenible. Guía para responsables políticos.

Sitio oficial Batea Mahuida-Parque de Nieve-Villa Pehuenia. (s.f.). Consultado en mayo de 2020 http://www.cerrobateamahuida.com/.

Sitio oficial Ministerio de Turismo de la Provincia del Neuquén. (s.f.). Consultado en mayo de 2020 http://neuquentur.gob.ar/es/.

Una comunidad mapuche abre un centro de esquí en Neuquén. (2000, 10 de julio). Clarín. https://www.clarin.com/sociedad/comunidad-mapuche-abre-centro-esquineuquen_0_rJ5KO9eRYg.html.

Volcán Batea Mahuida. (28 de agosto de 2019). En Wikipedia. https://es.wikipedia.org/wiki/Volc\%C3\%A1n_Batea_Mahuida.

Volcán Batea Mahuida. (s.f.). En Agencia de Turismo Patagonia Argentina. https://www.patagonia-argentina.com/volcan-batea-mahuida/.

\footnotetext{
"Visión de Futuro" Año 18, Volumen No 25 N 2, Edición Especial-III Congreso Regional de Economía del Norte Grande-Pág 56-79 URL de la Revista: http://visiondefuturo.fce.unam.edu.ar/index.php/visiondefuturo/index

URL del Documento: https://visiondefuturo.fce.unam.edu.ar/index.php/visiondefuturo/issue/view/20

ISSN 1668 - 8708 - Versión en Línea

E-mail: revistacientifica@fce.unam.edu.ar
} 


\section{RESUMEN BIOGRÁFICO}

\section{Micaela Abigail Spinelli}

Especialista en Economía del Turismo. Actual Becaria Doctoral del Centro de Investigación y Desarrollo del Turismo (CIDeTur) y docente de grado de la Escuela de Economía y Negocios de la Universidad de San Martin. Actual maestranda en Economía y Desarrollo del Turismo (UNSAM) y licenciada en Economía (UNSAM). 